\title{
ACERCA DEL CÓMPUTO DE LOS PLAZOS POR MESES
}

\author{
Benjamín GÓRRIZ GÓMEZ \\ Juez Sustituto de lo Contencioso-Administrativo \\ Tribunal Superior de Justicia de Cataluña \\ bjgorriz@gmail.com
}

\section{PRELIMINAR}

Aunque sea una obviedad, debe comenzarse indicando que mientras todos los días del año tienen la misma extensión temporal, veinticuatro horas, no ocurre lo mismo con los meses del año, pues uno tiene veintiocho y, a veces, veintinueve días, otros treinta, y otros treinta y uno. Ello constituye una de las razones por las que el cómputo de los plazos señalados por meses no ha dejado de plantear problemas, pues no siempre las distintas normativas aplicables ni la jurisprudencia que las interpreta ha sido coincidente en lo que debe entenderse por «mes».

A modo de constatación de lo dicho y centrándonos en el plazo de interposición del recurso contencioso-administrativo —al que se refieren la mayoría, que no todas, de las sentencias y autos que se citarán-, cabe hacer un breve recorrido cronológico recogiendo diferentes pronunciamientos que ponen de manifiesto las distintas formas o maneras de computar los plazos por meses, haciendo referencia primero, también brevemente, a la legislación aplicable.

\section{ANTECEDENTES}

\section{Legislación}

a) Legislación de la jurisdicción contencioso-administrativa

La Ley Santamaría de Paredes, Ley de 13 de septiembre de 1888 sobre el ejercicio de la jurisdicción contencioso-administrativa (publicada en la Gaceta de Madrid, núm. 258, de 14 de septiembre de 1888), estableció lo siguiente en su art. 7 : 
«El término para interponer el recurso contencioso-administrativo será en toda clase de asuntos el de tres meses, contados desde el día siguiente al de la notificación administrativa de la resolución reclamable» ${ }^{1}$.

Y en su art. 94:

«Los plazos que esta Ley señala por meses se contarán por meses enteros, sin tomar en cuenta el número de días de que se compongan ni los feriados, y los meses se entenderán de treinta días.

Al computarse los plazos señalados por días, se descontarán los feriados, y si en uno de éstos espirase el término, se entenderá prorrogado hasta el primer día hábil siguiente.

Los términos señalados para utilizar los recursos contencioso-administrativos y los de revisión y nulidad correrán durante las vacaciones del verano.

Los términos fijados en esta ley empezarán a correr desde el día siguiente al en que se hubiere hecho el emplazamiento, citación o notificación, y se contará en ellos el día del vencimiento. No podrán reducirse ni ampliarse por el Tribunal sino en los casos en que se le conceda expresamente la facultad de hacerlo.

El transcurso de un término señalado para el ejercicio de algún derecho producirá el efecto de la pérdida de este derecho».

La Ley reformada sobre el ejercicio de la jurisdicción contencioso-administrativa de 22 de junio de 1894 (Gaceta de Madrid, núm. 183, de 2 de julio de 1894) modificó ligeramente la redacción del art. 94, desapareciendo la expresión «y los meses se entenderán de treinta días», de manera que el primer párrafo del art. 94 pasó a tener el siguiente tenor:

«Los plazos que esta Ley señala por meses se contarán por meses enteros, sin tomar en cuenta el número de días de que se compongan, ni los feriados».

La situación no varía con el texto refundido de 1952 (BOE, de 16 de marzo de 1952).

Tanto la Ley de 13 de septiembre de 1888 como la reformada de 22 de junio de 1894 dispusieron en su art. 105 que:

${ }^{1}$ Según el mismo precepto, el término era de cuatro y seis meses, respectivamente, cuando la persona que hubiere de reclamar tuviera su residencia en las Antillas españolas o en Filipinas y posesiones del Golfo de Guinea, y de nueve meses en los Archipiélagos de las Marianas o de las Carolinas. 
«La Ley de Enjuiciamiento Civil regirá como supletoria de la legislación que contiene los procedimientos contencioso-administrativos, siendo aplicable en todo lo que fuere compatible con la índole de los mismos» ${ }^{2}$.

Por último, la Ley Reguladora de la Jurisdicción Contencioso-Administrativa de 27 de diciembre de 1956 estableció en su art. 58 que:

«El plazo para interponer el recurso contencioso-administrativo será de dos meses, contados desde el día siguiente a la notificación del acuerdo resolutorio del recurso de reposición, si es expreso».

Y la vigente Ley de 13 de julio de 1988 en su art. 46 estableció que:

«El plazo para interponer el recurso contencioso-administrativo será de dos meses contados desde el día siguiente al de la publicación de la disposición impugnada o al de la notificación o publicación del acto que ponga fin a la vía administrativa, si fuera expreso».

\section{b) Legislación procesal civil}

La Ley de Enjuiciamiento Civil de 3 de febrero de 1881 dispuso en el art. 303 lo que sigue:

«Los términos judiciales empezarán a correr desde el día siguiente al en que se hubiere hecho el emplazamiento, citación o notificación, y se contará en ellos el día del vencimiento».

Y en el art. 305:

«Los términos señalados por meses se contarán por meses naturales, sin excluir los días inhábiles. En estos casos, si el plazo concluyese en domingo u otro día inhábil, se entenderá prorrogado al siguiente día hábil».

El texto de los preceptos citados no varía después de la importante reforma operada por la Ley 34/1984, de 6 de agosto, de Reforma Urgente de la Ley de Enjuiciamiento Civil.

2 Aunque más adelante se transcriben los preceptos de la Ley de Enjuiciamiento Civil referidos al cómputo de plazos, no se aborda en este breve estudio la polémica sobre si dicha ley procesal resultaba aplicable o no, supletoriamente, al cómputo del plazo de interposición del recurso contencioso-administrativo. 
La vigente Ley 1/2000, de 7 de enero, de Enjuiciamiento Civil, dedica su art. 133 al cómputo de los plazos con el siguiente contenido:

«1. Los plazos comenzarán a correr desde el día siguiente a aquel en que se hubiere efectuado el acto de comunicación del que la Ley haga depender el inicio del plazo, y se contará en ellos el día del vencimiento, que expirará a las veinticuatro horas.

No obstante, cuando la Ley señale un plazo que comience a correr desde la finalización de otro, aquél se computará, sin necesidad de nueva notificación, desde el día siguiente al del vencimiento de éste.

2. En el cómputo de los plazos señalados por días se excluirán los inhábiles.

Para los plazos que se hubiesen señalado en las actuaciones urgentes a que se refiere el apartado 2 del art. 131 no se considerarán inhábiles los días del mes de agosto y sólo se excluirán del cómputo los domingos y festivos.

3. Los plazos señalados por meses o por años se computarán de fecha a fecha.

Cuando en el mes del vencimiento no hubiera día equivalente al inicial del cómputo, se entenderá que el plazo expira el último del mes.

4. Los plazos que concluyan en domingo u otro día inhábil se entenderán prorrogados hasta el siguiente hábil».

A los efectos que aquí interesan, la situación no varía tras la Ley 13/2009, de 3 de noviembre, sobre reforma de la legislación procesal para la implantación de la nueva oficina judicial, puesto que aun cuando modificó la redacción de los apartados 2 y 4 anteriores, lo fue para considerar inhábiles, además de los domingos y festivos, los sábados.

\section{c) Código Civil}

Por su parte, el Código Civil de 1889 estableció en su art. 7 lo siguiente:

«Si en las leyes se habla de meses, días o noches, se entenderá que los meses son de treinta días, los días de veinticuatro horas y las noches desde que se pone hasta que sale el sol. Si los meses se determinan por sus nombres, se computarán por los días que respectivamente tengan».

Se mantiene aquí la referencia a los meses de treinta días desaparecida del art. 94 en la Ley Reformada de la Jurisdicción Contencioso-Administrativa de 1894. 
Más adelante, tras la reforma del título preliminar en 1974, el art. 5 del Código Civil pasó a tener la siguiente redacción:

«1. Siempre que no se establezca otra cosa, en los plazos señalados por días, a contar de uno determinado, quedará éste excluido del cómputo, el cual deberá empezar en el día siguiente, y si los plazos estuviesen fijados por meses o años, se computarán de fecha a fecha. Cuando en el mes del vencimiento no hubiera día equivalente al inicial del cómputo, se entenderá que el plazo expira el último del mes.

2. En el cómputo civil de los plazos no se excluyen los días inhábiles».

\section{d) Legislación de procedimiento administrativo}

La Ley de Bases para la Redacción de Reglamentos de Procedimiento Administrativo de los Departamentos Ministeriales de 19 de octubre de 1889 (Gaceta de Madrid, núm. 298, de 25 de octubre de 1889) no estableció forma o manera de cómputo de plazos, y la Ley de Procedimiento Administrativo de 17 de julio de 1958 — que deroga la Ley de Bases de 1889 y los reglamentos dictados para su ejecución- estableció en su art. 59 que:

«Los plazos se contarán siempre a partir del día siguiente a aquel en que tenga lugar la notificación o publicación del acto de que se trate.

$\mathrm{Y}$ en su art. 60 que:

«1. Siempre que no se exprese otra cosa, cuando los plazos se señalen por días, se entiende que éstos son hábiles, excluyéndose del cómputo los feriados.

2. Si el plazo se fija en meses, éstos se computarán de fecha a fecha. Si en el mes del vencimiento no hubiere día equivalente a aquel en que comienza el cómputo, se entenderá que el plazo expira el último día del mes. Si en años, se entenderán naturales en todo caso.

3. Cuando el último día del plazo sea inhábil, se entenderá prorrogado al primer día hábil siguiente».

La Ley 30/1992, de 26 de noviembre, de Régimen Jurídico de las Administraciones Públicas y del Procedimiento Administrativo Común, estableció en su art. 48, dedicado al cómputo de plazos y términos, lo siguiente:

«1. Siempre que no se exprese otra cosa, cuando los plazos se señalen por días, se entiende que éstos son hábiles, excluyéndose del cómputo los domingos y los declarados festivos. 
Cuando los plazos se señalen por días naturales, se hará constar esta circunstancia en las correspondientes notificaciones.

2. Si el plazo se fija en meses o años, éstos se computarán de fecha a fecha. Si en el mes de vencimiento no hubiera día equivalente a aquel en que comienza el cómputo, se entenderá que el plazo expira el último día del mes.

3. Cuando el último día del plazo sea inhábil, se entenderá prorrogado al primer día hábil siguiente.

4. Los plazos expresados en días se contarán a partir del día siguiente a aquel en que tenga lugar la notificación o publicación del acto de que se trate o, en su caso, de acuerdo con lo dispuesto por el art. 44.5.

Los restantes plazos se contarán a partir del día de la notificación o publicación del correspondiente acto, salvo que en él se disponga otra cosa, y respecto de los plazos para iniciar un procedimiento, a partir del día de la fecha en que la solicitud haya tenido entrada en cualquiera de los registros del órgano administrativo competente».

La Ley 4/1999, de 13 de enero, de modificación de la Ley 30/1992, dio nueva redacción al art. 48, en los siguientes términos:

«1. Siempre que por ley o normativa comunitaria europea no se exprese otra cosa, cuando los plazos se señalen por días, se entiende que éstos son hábiles, excluyéndose del cómputo los domingos y los declarados festivos.

Cuando los plazos se señalen por días naturales, se hará constar esta circunstancia en las correspondientes notificaciones.

2. Si el plazo se fija en meses o años, éstos se computarán a partir del día siguiente a aquel en que tenga lugar la notificación o publicación del acto de que se trate, o desde el siguiente a aquel en que se produzca la estimación o desestimación por silencio administrativo. Si en el mes de vencimiento no hubiera día equivalente a aquel en que comienza el cómputo, se entenderá que el plazo expira el último día del mes.

3. Cuando el último día del plazo sea inhábil, se entenderá prorrogado al primer día hábil siguiente.

4. Los plazos expresados en días se contarán a partir del día siguiente a aquel en que tenga lugar la notificación o publicación del acto de que se trate, o desde el siguiente a aquel en que se produzca la estimación o la desestimación por silencio administrativo».

De esta manera, y mientras en la redacción originaria de la Ley 30/1992 los plazos por días se cuentan «a partir del día siguiente» a aquel en que tenga lugar la notificación o publicación del acto y los restantes plazos - y, por tanto, los señalados por meses - se cuentan «a partir del día de la notificación o publicación del correspondiente acto», tras la modificación de 
la Ley 4/1999, tanto los plazos fijados por días como por meses se computan «a partir del día siguiente» a aquel en que tenga lugar la notificación o publicación del acto.

\section{Jurisprudencia ${ }^{3}$}

\section{a) Cómputo por meses enteros}

1. Notificado el acuerdo impugnado el 24 de febrero de 1903, el escrito de interposición presentado el 25 de mayo es extemporáneo [Auto del Tribunal Supremo de 6 de julio de 1904 (ROJ ${ }^{4}$ : ATS 118/1904ECLI:ES:TS:1904:118A)].

2. Computado el plazo de tres meses «como determina el art. 94 de la misma [Ley de la Jurisdicción Contencioso-Administrativa de 1894], o sea, por meses enteros, sin tener en cuenta el número de días de que se compongan ni los feriados, el plazo para impugnar una real orden notificada el 10 de agosto venció el 10 de noviembre siguiente», y, por tanto, el recurso interpuesto el día 11 lo fue fuera de plazo [STS de 10 de julio de 1913 (ROJ: STS 926/1913-ECLI:ES:TS:1913:926)].

3. «Considerando que si la fecha de la notificación es la dicha de 28 de enero de 1914, el plazo legal de tres meses para interponer el recurso contencioso contra la real orden, contad[o] como previene el art. 94 de la ley, expiró en 28 de abril siguiente», por lo que no habiéndose interpuesto hasta el 29 de dicho mes procede estimar la excepción de prescripción de la acción [STS de 8 abril de 1919 (ROJ: STS 744/1919-ECLI:ES:TS:1919:744)].

4. Denegado el recurso de reposición el día 25 de marzo de 1926 $\ll y$, consecuentemente, comenzado el plazo del $\mathrm{mes}^{5}$ antes aludido para la interposición del recurso contencioso-administrativo el 26 de marzo predicho, finó el término el 25 del siguiente abril, dentro del cual no se impug-

\footnotetext{
${ }^{3}$ Como se ha dejado dicho, la mayoría de las resoluciones que se citarán se refieren al plazo de interposición del recurso contencioso-administrativo.

${ }^{4}$ ROJ: acrónimo de «Repertorio Oficial de Jurisprudencia». Es el número con el que el Centro de Documentación Judicial (Cendoj) del Consejo General del Poder Judicial identifica las resoluciones.

5 El plazo de interposición no era único, pues determinadas normas sectoriales establecían otros distintos al del art. 7 de la Ley sobre el ejercicio de la jurisdicción contenciosoadministrativa. Así, el art. 38 del Reglamento de Procedimiento Municipal de 23 de agosto de 1924 establecía el de un mes, a contar desde el día siguiente.
} 
nó el acuerdo, ya que lo fue en el siguiente día 26, cuando ya el término legal se hallaba extinguido» [STS de 14 de marzo de 1930 (ROJ: STS 2721/1930-ECLI:ES:TS:1930:2721)].

5. La real orden impugnada «le fue notificada en 19 del mismo mes de abril, como así también se reconoce en la demanda; por tanto, el plazo de los tres meses que el art. $7 .^{\circ}$ de la Ley señala para interponer el recurso contencioso-administrativo terminaba el 19 de julio» [STS de 26 abril de 1930 (ROJ: STS 2275/1930-ECLI:ES:TS:1930:2275)].

6. «[H]abiendo sido notificada la resolución impugnada en este pleito el día 29 de marzo de 1928, según consta en cédula firmada por el recurrente, el plazo para interponer el recurso empezó a correr desde el día siguiente inclusive, o sea, desde el día 30 de dicho mes, y por ser de tres meses el plazo, ellos expiraron el día 29 de junio de 1928» [STS de 28 de junio de 1930 (ROJ: STS 591/1930-ECLI:ES:TS:1930:591)].

7. Publicada la resolución impugnada en la Gaceta de Madrid el 6 de octubre de 1928 «conforme a los arts. 7, párrafo primero, y 94, párrafo primero, y 4 de la indicada Ley, es evidente que el plazo impugnatorio para el Sr. ... comenzó el día 7 de octubre de 1928 y concluyó el 6 de enero inmediato», por lo que el interpuesto el día 7 de enero de 1929 lo fue después de expirado el término legal [STS de 15 de marzo de 1932 (ROJ: STS 99/1932-ECLI:ES:TS:1932:99)].

8. Notificada la parte recurrente el día 8 de enero de 1936 y «teniendo en cuenta que el escrito interponiendo el recurso fue presentado en el Juzgado de Guardia para su remisión a este Tribunal Supremo a las veintitrés horas del día 9 de abril del citado año 1936 [...] es evidente que fue entablado el recurso después de finalizado el plazo establecido en el art. 7. ${ }^{\circ}$ de la Ley de la Jurisdicción de 22 de junio de 1894, pues siendo éste el de tres meses, los cuales han de contarse, según ordena el art. 94 de la misma Ley, por meses enteros, sin tomar en cuenta el número de días de que se compongan, empezando a correr desde el día siguiente a la notificación, y se contará el del vencimiento» [STS de 20 de octubre de 1948 (ROJ: STS 171/1948-ECLI:ES:TS:1948:171)].

9. «Considerando que el art. $7 .^{\circ}$ de nuestra Ley Jurisdiccional de 22 de junio de 1894 dispone que el término legal para interponer el recurso contencioso-administrativo será, en toda clase de asuntos, el de tres meses, contados desde el día siguiente al de la notificación de la resolución reclamada, y que, según el art. 94 de la misma Ley, los plazos señalados por meses se contarán por meses enteros, sin tener en cuenta el número de días de que se compongan, por todo lo cual, a tenor de dichas normas legales, 
y publicada como fue en la Gaceta de Madrid del 14 de enero de 1936 la Orden del Ministerio de Agricultura del día 10 de los mismos mes y año, contra la cual se interpuso el actual recurso, es indudable que desde el 15 de enero, día siguiente al de tal publicación, ha de empezarse a computar el plazo legal, que concluyó, por tanto, con el día 14 de abril de 1936, y como el escrito inicial de interposición de este recurso se presentó después de tal fecha ${ }^{6}$, es visto que ello fue cuando el término había ya expirado, y procede, en consecuencia, declarar prescrita la acción para interponerle, como el art. 46 de la citada Ley previene» [STS 21 de octubre de 1948 (ROJ: STS 173/1948-ECLI:ES:TS:1948:173)].

10. Notificada la resolución impugnada el día 16 de julio de 1949 y no presentado el escrito interponiendo el recurso «hasta el día 17 de octubre del mismo año, o sea, después de haber transcurrido el último día del plazo para su interposición, es evidente que lo hizo cuando había fenecido el término establecido por la Ley» [STS de 2 de junio de 1955 (ROJ: STS 1089/1955-ECLI:ES:TS:1955:1089)].

11. Notificado el acuerdo el día 6 de octubre de 1959 y presentado el escrito inicial interponiendo el recurso contencioso-administrativo el día 7 de diciembre del mismo año, «es manifiesto que el plazo de dos meses había expirado el día anterior, 6 de diciembre [...] dado que el plazo para interposición del recurso jurisdiccional es de ejercicio de una acción, contándose por ese carácter los meses del mismo, de fecha a fecha, sin consideración a los días feriados» [STS de 25 abril de 1960 (ROJ: STS 306/1960-ECLI:ES:TS:1960:306)].

12. Notificada la resolución al recurrente el día 2 de junio de 1959, «el plazo de dos meses establecido por el párrafo primero del art. 58 de la Ley reguladora de esta jurisdicción empezó a contarse el día 3 de junio y terminó, por tanto, el 2 de septiembre de dicho año 1959», por lo que la interposición del recurso contencioso-administrativo el 3 de septiembre lo es después de haber expirado el plazo para ello [STS de 9 de diciembre de 1960 (ROJ: STS 1151/1960-ECLI:ES:TS:1960:1151)].

13. Notificada la resolución impugnada el 21 de diciembre de 1959 y presentado el escrito promoviendo el recurso contencioso-administrativo el día 22 de febrero de 1960, de acuerdo «con el sistema de cómputo de fecha a fecha que la jurisprudencia de este Tribunal tiene establecido con reiteración cuando se trata de plazos señalados por meses, es indude 1936.

${ }^{6}$ Según los considerandos de la propia STS, el recurso se interpuso el 15 de abril 
dable que en el caso sometido a estudio expiró el día 21 de febrero de 1960» [STS de 19 de diciembre de 1960 (ROJ: STS 1137/1960-ECLI:ES :TS:1960:1137)].

Teniendo en cuenta que, conforme a lo preceptuado en la Ley reformada de 1894, el plazo para interponer el recurso contencioso-administrativo se cuenta «desde el día siguiente al de la notificación administrativa de la resolución» (art. 7) y que los plazos señalados por meses «se contarán por meses enteros, sin tomar en cuenta el número de días de que se compongan ni los feriados», resulta que el plazo para impugnar una determinada resolución comienza el día siguiente de la notificación y termina, computado por meses enteros sin tomar en cuenta el número de días de que se compongan -ni los feriados-, el día que coincide con el ordinal anterior al en que comienza. Y este sistema de cómputo del plazo es seguido en todas las resoluciones del Tribunal Supremo antes mencionadas. Así, en la señalada bajo el número 1 (ATS de 6 de julio de 1904), producida la notificación el 24 de febrero, el plazo comienza el día siguiente ( 25 de febrero) y termina el día que coincide con el numeral anterior a éste (día 24), por lo que la interposición el día 25 es extemporánea. En la señalada bajo el número 2 (STS de 10 de julio de 1913), producida la notificación el 10 de agosto, el plazo de interposición comienza el día siguiente (11 de agosto) y termina el día que coincide con el numeral anterior a éste (día 10 de noviembre), por lo que el recurso interpuesto el día 11 lo fue fuera de plazo. En la señalada bajo el número 3 (STS de 8 abril de 1919), producida la notificación el 28 de enero, el plazo comienza el día siguiente ( 29 de enero) y termina el día que coincide con el numeral anterior a éste (día 28 de abril), por lo que al ser interpuesto el recurso el 29 de dicho mes procede estimar la excepción de prescripción de la acción, etc.

Por tanto, el plazo comienza el día siguiente de la notificación y termina, computado por meses enteros, sin tomar en cuenta el número de días de que se compongan —ni los feriados—, el día que coincide con el ordinal anterior al en que comienza, que coincide con el día de la notificación. El cómputo realizado con arreglo al art. 94 de la Ley Jurisdiccional de 1894 era no por meses de treinta días naturales — como establecía el art. 7 del Código Civil—, sino por meses naturales — sin tomar en cuenta el número de días de que se compongan-. Sistema de cómputo que acabó denominándose «de fecha a fecha» - como lo designa expresamente la STS de 25 de abril de 1960, antes reseñada—, por ser iguales la inicial y la final del cómputo. Pero bien entendido que las fechas de cómputo no eran las de inicio y final del plazo, sino que se computaba desde determi- 
nada fecha, la de notificación o publicación del acto hasta la misma fecha, en el mes correspondiente, que era la de finalización del plazo.

\section{b) Cómputo de sesenta días naturales}

Derogada la Ley de la Jurisdicción Contencioso-Administrativa de 1894, el art. 58 de la nueva Ley Reguladora de la Jurisdicción ContenciosoAdministrativa de 1956 se limitó a fijar el plazo de interposición del recurso contencioso-administrativo en dos meses, «contados desde el día siguiente a la notificación del acuerdo resolutorio del recurso de reposición, si es expreso». Por otra parte, como se ha dejado dicho, el art. 7 del Código Civil de 1889 — antes de la modificación del título preliminar de 1974- establecía que «si en las leyes se habla de meses, días o noches, se entenderá que los meses son de treinta días, los días de veinticuatro horas y las noches desde que se pone hasta que sale el sol». Así las cosas, el plazo de interposición que en la Ley Jurisdiccional de 1894 se contaba «por meses enteros, sin tomar en cuenta el número de días de que se compongan ni los feriados» y que en la práctica se denominó «de fecha a fecha», pasó a ser con la Ley Jurisdiccional de 1956 por meses de treinta días naturales, por lo que dicho plazo de dos meses pasó a ser de sesenta días naturales, contados a partir del siguiente al de la notificación.

1. La notificación del acuerdo administrativo se verificó el 14 de octubre de 1959 y el recurso contencioso-administrativo se interpone el 14 de diciembre del mismo año. No habiendo determinado la Ley Jurisdiccional de 1956 la forma de computar el plazo de interposición de dos meses, «es preciso para hacerlo acudir a los preceptos pertinentes de la Ley de Enjuiciamiento. Civil, por el carácter supletorio que le atribuye la disposición adicional sexta de aquélla, y a los del título preliminar del Código Civil en [que] se sientan las reglas generales para la aplicación de las leyes. Considerando que el art. 305 de la referida Ley adjetiva ordena que los términos señalados por meses se contarán por meses naturales, sin excluir los días inhábiles, y el 7. ${ }^{\circ}$ del Código mencionado establece que cuando en las leyes se hable de meses se entenderán que son de treinta días, salvo que se designen por sus nombres, deduciéndose de esta normación que los sesenta días naturales a que equivalen, según ella, los dos meses fijados por la Ley Jurisdiccional, contados desde el siguiente al en que tuvo lugar la notificación del acuerdo, terminaron el 13 de diciembre». Por lo que el recurso interpuesto el día 14 es extemporáneo al haber sido formulado un día des- 
pués del vencimiento del término [STS de 19 de abril de 1961 (ROJ: STS 1603/1961-ECLI:ES:TS:1961:1603)].

2. Notificada la resolución el 20 de julio de 1961 y presentado el escrito inicial del recurso contencioso-administrativo en 20 de septiembre posterior inmediato, «es visto que había transcurrido ya el plazo de dos meses establecido en el párrafo 1 del art. 58 de la Ley Jurisdiccional del 27 de diciembre de 1956 para su interposición, computando el mismo de acuerdo tanto con el art. 305 de la Ley de Enjuiciamiento Civil, el cual dispone que "los términos señalados por meses se contarán por meses naturales, sin incluir los días inhábiles" — cuyas normas son supletorias de lo no previsto en la Ley Jurisdiccional según su disposición adicional sexta—, como de conformidad con el art. 7. ${ }^{\circ}$ del Código Civil, que establece que "se entenderá que los meses son de treinta días», por lo que es de acoger la propuesta de inadmisibilidad de la acción ejercitada en estas actuaciones" $\gg$ [STS de 9 de mayo de 1962 (ROJ: STS 1609/1962-ECLI:ES:TS:1962:1609)].

3. «Con arreglo a lo dispuesto en el art. 58, número 1, de la mentada Ley Jurisdiccional, el plazo para interponer el recurso contencioso-administrativo será de dos meses contados desde el día siguiente a la notificación del acuerdo resolutorio con lo que previene la disposición adicional sexta del propio texto legal, deberá computarse que las normas de la Ley de Enjuiciamiento Civil, la que en su art. 305 dispone que los términos señalados por meses se contarán por meses naturales sin excluir los días inhábiles, debiendo entenderse que tales meses son de treinta días, porque así lo dispone el art. 7 del Código Civil que es de general aplicación, criterio que, recogido por la doctrina de este Supremo Tribunal en múltiples sentencias, entre las que figuran las de 9 de mayo y 5 de diciembre de 1959 que reiteran el criterio mentado por la Sala de Gobierno en acuerdo de fecha 18 de octubre de 1957, ha modificado el que al amparo de la legislación revocada sobre procedimiento contencioso-administrativo hubo de aplicarse precedentemente». En el caso, la resolución fue notificada el día 9 de diciembre de 1959 y el escrito de interposición del recurso se presentó el día 9 de febrero de 1960, por lo que «es indudable que la presentación se hizo a los dos meses naturales más dos días, puesto que diciembre y enero tienen treinta y un días cada uno, lo que demuestra que fue presentado fuera del plazo legal, que en el caso de autos expiraba el día 7 del expresado mes de febrero» [STS de 24 de septiembre de 1962 (ROJ: STS 2304/1962-ECLI:ES:TS:1962:2304)].

4. La resolución fue notificada a los actores el día 30 de junio de 1961, mientras que el recurso contencioso-administrativo se presentó en 
30 de agosto siguiente, lo que evidencia el transcurso de sesenta y un días entre una y otra fecha, habida cuenta de que el mes de julio tiene treinta y un días. «Considerando que según lo dispuesto por el art. 305 de la Ley de Enjuiciamiento Civil los términos señalados por meses se contarán por meses naturales, sin excluir los días inhábiles, no debe darse otra interpretación correcta a tal disposición que la que se derive de la única característica diferencial que ofrece el propio texto, o sea, que mes natural es aquel en que se cuentan todos los días, tanto hábiles como inhábiles, a diferencia del que no lo es, en el cual cabe hacer descuento de los días feriados; pero esa distinción no autoriza a estimar que el mes natural haya de estar integrado por más o menos de treinta periodos de veinticuatro horas, pues semejante disposición no se contiene en el texto literal del precepto ni siquiera implícita en su espíritu, por cuya razón no puede apreciarse antinomia entre el mencionado artículo y el $70^{\circ}$ del Código Civil cuando éste preceptúa que, si en las leyes se habla de meses, se entenderá que son de treinta días, con la sola excepción de los meses que se determinan por sus nombres, los que se computarán por los días que respectivamente tengan, concepto éste completamente distinto al de mes natural, como puede advertirse del mismo contexto del referido artículo, desprendiéndose de todo ello que ambos preceptos se complementan al aclarar el Código lo dispuesto en la Ley Procesal; mas, aunque así no fuere y se admitiera — sólo en hipótesis- que entre ambos artículos existe antinomia, únicamente podría ser resuelta en favor de lo dispuesto por el Código, toda vez que es de fecha posterior, con la consiguiente fuerza derogatoria, amén de que sienta la norma explícita y concreta, y, sobre todo, porque el mencionado art. $7 .^{\circ}$, tanto por hallarse comprendido en el título preliminar del Código — que es de general observancia dado el carácter normativo de sus preceptos- como por obedecer su ratio legis a la necesidad de aclarar el sentido de las leyes en un determinado extremo, está dotado de prevalente fuerza de obligar. Considerando que el criterio que se deja expuesto se muestra acorde con el mantenido en términos generales por la doctrina jurisprudencial, tanto en la jurisdicción civil, como se aprecia en las Sentencias de 24 de octubre de 1903, 23 de junio de 1919, 6 de julio de 1923, 26 de enero de 1929 y 21 de mayo de 1931, como en esta jurisdicción, según Sentencias de 17 de junio de 1957, 7 de mayo de 1960, SO (sic) de mayo de 1961 y 25 de febrero de 1963, entre otras varias, la última de las cuales ha sido pronunciada por la Sala de Revisión de lo Contencioso-Administrativo de este Tribunal». Por todo ello, el recurso inicial de estas actuaciones fue interpuesto fuera del plazo establecido en el art. 58 de la Ley Jurisdiccional, de manera que procede hacer la 
consiguiente declaración de inadmisibilidad [STS de 14 de marzo de 1963 (ROJ: STS 238/1963-ECLI:ES:TS:1963:238)].

5. El art. 305 de la Ley de Enjuiciamiento Civil y el art. 7 del Código Civil, como tiene ya declarado en forma reiterada la doctrina jurisprudencial, tanto en materia civil como en lo contencioso-administrativo, «lejos de contradecirse, resultan complementados y armónicos, a más de que, en el supuesto de que no fuere así, habría de prevalecer el del Código Civil por ser posterior a la ley rituaria y estar dotado de fuerza derogatoria, al igual que por la general observancia que a todas las disposiciones de su título preliminar les corresponde y por el carácter supletorio que a sus preceptos les asigna el art. 16 del propio cuerpo legal, criterio este recogido por la jurisdicción civil en múltiples sentencias, entre las que figuran las de 24 de octubre de 1903, 23 de junio de 1919, 6 de julio de 1923, 26 de enero de 1929 y 21 de mayo de 1951, y también por esta jurisdicción, entre otras sentencias en las de 17 de junio de 1957, 7 de mayo de 1960, 30 de mayo de 1961, 25 de febrero de 1963 y 14 de marzo de ese mismo año, la penúltima de ellas pronunciada por la Sala Especial de Revisión de lo Contencioso-Administrativo de este Supremo Tribunal, sin que frente a la expuesta doctrina puedan invocarse con eficacia los preceptos de las Leyes de Procedimiento Administrativo y Económico-Administrativo, según las cuales el cómputo de los meses debe hacerse de fecha a fecha, toda vez que dichas disposiciones no son aplicables en forma directa ni subsidiaria en el procedimiento contencioso-administrativo, que tiene previstas sus fuentes de Derecho, conforme se hace constar con antelación». En el caso concreto, notificado el acuerdo a la recurrente el día 14 de diciembre de 1959 y presentado el recurso contencioso el día 13 de febrero de 1960, «es evidente que lo ha sido cuando ya había transcurrido el plazo de dos meses que señala el antes invocado art. 58 de la Ley de la Jurisdicción, puesto que de una a otra fecha mediaron sesenta y un días, dando lugar con ello al motivo de inadmisibilidad del recurso previsto en el art. 82, caso $f$ ), del texto legal últimamente citado». [STS de 23 de diciembre de 1963 (ROJ: STS 1718/1963-ECLI:ES:TS:1963:1718)].

6. «Como reiteradamente viene declarando la jurisprudencia de las Salas de lo Contencioso-Administrativo de este Tribunal, los plazos procesales señalados por meses contarán como de treinta días, si no se determinan por sus nombres, a tenor del art. 7 del Código Civil». En el caso, notificada la resolución impugnada el día 5 de septiembre de 1964, la interposición del recurso el día 5 de noviembre siguiente lo fue cuando el plazo legal había fenecido, pues terminó «el día 4 de noviembre a las doce 
de la noche - ya que hay que computar veinticinco días de septiembre, treinta y uno de octubre, y cuatro de noviembre-, último día que, por no ser feriado, debe entrar en el cómputo» [STS de 20 de octubre de 1965 (ROJ: STS 481/1965-ECLI:ES:TS:1965:481)].

7. «Si bien no puede desconocerse que al ponerse en práctica los preceptos rituarios de la Ley de la Jurisdicción, la jurisprudencia de las distintas Salas de este Tribunal sustentaron criterios dispares en la forma de computar este plazo, es lo cierto que todas ellas en forma unánime y reiteradísima entendieron después que el plazo de interposición es de sesenta días naturales, ya que la Ley habla de dos meses, y éstos, de conformidad a lo dispuesto en el art. $7 .^{\circ}$ del Código Civil, son de treinta días, criterios los antes aludidos que unificó la Sala Especial de Revisiones con su muy autorizado criterio en su sentencia [de 25 de febrero de 1963] citada en la resolución recurrida en el sentido que ahora se hace». Por ello, verificada la notificación de la resolución impugnada el día 23 de julio de 1966, el recurso contencioso-administrativo interpuesto el día 22 de septiembre resulta extemporáneo, pues el plazo terminó el día antes de la presentación [STS de 4 de marzo de 1968 (ROJ: STS 2585/1968-ECLI:ES:TS:1968:2585)].

\section{c) Cómputo de fecha a fecha}

La Ley de Procedimiento Administrativo de 1958 estableció que los plazos fijados por meses se computarán de fecha a fecha. Posteriormente, la reforma de 1974 del título preliminar del Código Civil también dispuso que los plazos por meses se computarán de fecha a fecha, lo que, según alguna de las sentencias que luego se citarán, respondió al criterio de unificar el cómputo de los plazos con la Ley de Enjuiciamiento Civil y con la de Procedimiento Administrativo.

1. «Las dudas suscitadas en torno a si el plazo de dos meses establecido en el art. 58.1 de la Ley de esta Jurisdicción debe contarse por días o de fecha a fecha han sido totalmente eliminadas con la reforma del Código Civil, articulada por texto de 1 de mayo de 1974, pues su nuevo art. 5 unifica el conjunto de plazos señalados por meses o años al previsto en el art. 305 de la Ley de Enjuiciamiento Civil, estableciendo el sistema de fecha a fecha». En el caso de autos, el acuerdo recurrido fue notificado el 8 de agosto y el recurso contencioso fue interpuesto el 8 de octubre, esto es, «el último día del plazo legal y, por tanto, dentro del mismo» [STS de 21 de febrero de 1979 (ROJ: STS 1078/1979-ECLI:ES:TS:1979:1078)]. 
2. «Si bien es cierto que este Alto Tribunal vino consagrando reiteradamente - Sentencias de 25 de febrero de 1963, 7 de febrero, 16 de abril y 6 de octubre de 1975, y 27 de mayo de 1977- la doctrina, que el abogado del Estado propugna, de computar el plazo de dos meses como de sesenta días naturales por aplicación del art. 7 del Código Civil, que disponía que: "Si en las leyes se habla de meses, días o noches, se entenderá que los meses son de treinta días, los días de veinticuatro horas y las noches desde que se pone hasta que sale el sol"; sin embargo, al aprobarse por el Decreto de 31 de mayo de 1974, publicado en el Boletín Oficial del Estado de 9 de julio siguiente, la reforma del título preliminar del Código Civil y disponer el art. 5 en esta nueva redacción que los meses se contarán de fecha a fecha, precepto aplicable al supuesto que se enjuicia [...] la jurisprudencia de este Tribunal Supremo interpretativa del precepto sostiene que el art. 7 del Código Civil resulta inoperante al modificarse el precepto; razones que impiden acoger la alegación de inadmisibilidad propuesta por el defensor de la Administración» [STS de 20 de abril de 1979 (ROJ: STS 3556/1979-ECLI:ES:TS:1979:3556)].

3. La disposición impugnada fue publicada en el Boletín Oficial del Estado de 12 de agosto de 1945 y recurrida el 13 de octubre del mismo año. La extemporaneidad del recurso es rechazada en atención a las siguientes razones: «a) a que el plazo de dos meses establecido para supuestos como el que nos ocupa (art. 58.32 de la propia Ley) se ha de contar "desde el día siguiente al de la última publicación oficial del acto o disposición" [art. 58.3.b)]; b) a que dicho plazo, al venir fijado por meses, se ha de computar "de fecha a fecha", de acuerdo con la nueva regulación del título preliminar del Código Civil (art. 5.1 del Decreto de 31 mayo 1974, aprobatorio de su texto articulado) y con la que ya venía establecida en el art. 60.2 de la Ley de Procedimiento Administrativo de 17 de julio de 1958; c) a que el día inicial no se cuenta (dies a quo non computatur in termino), mientras que el final se ha de contar por entero (dies ultimus pro completo habetur), puntualización esta última que no figura expresamente en la vigente Ley de la Jurisdicción, a diferencia de lo manifestado en la antigua (art. 102.4), sin duda por figurar en la Ley de Enjuiciamiento Civil (art. 304), dado el carácter supletorio de ésta, respecto de la nuestra (disposición final sexta); d) a que en ese cómputo de fecha a fecha, y puesto que el día inicial es el 12 de agosto, mejor dicho, el siguiente a éste, el final sería el 12 de octubre», añadiendo la STS que, dado que el 12 de octubre era inhábil — por ser domingo y la festividad de la Virgen del Pilar-, el dies ad quem se prolongaba al siguiente: 13 de octubre, fecha en que se presentó el escrito de 
interposición [STS de 2 de noviembre de 1979 (ROJ: STS 1442/1979-ECL I:ES:TS:1979:1442)].

4. «El cómputo de dos meses hay que realizarlo a partir de la vigencia del nuevo título preliminar del Código Civil, como ordena su art. 5.1, y en los plazos señalados por meses se computarán de fecha a fecha, por lo que publicada la orden impugnada en el Boletín Oficial del Estado del día 3 de diciembre de 1976, hasta el mismo día 3 del siguiente febrero no vencía el plazo y, por ello, al ser presentado el día 2 de dicho mes lo fue dentro del plazo legal» [STS de 1 de diciembre de 1980 (ROJ: STS 2225/1980-ECLI :ES:TS:1980:2225)].

5. El cómputo del plazo «ha de acomodarse a las nuevas exigencias que impone el nuevo sistema de cómputo establecido por el art. 5, número 1, del texto articulado del titulo preliminar del Código Civil con apoyo en la Ley de Bases de 17 de marzo de 1973 al preceptuar que "si los plazos estuviesen fijados par meses o años se computarán de fecha a fecha", con lo que se logra uniformidad en una cuestión que había sido polémica y de gran trascendencia, eliminando, además, el problema de la duración de los meses, al instaurar el sistema de los meses naturales, que deben contarse como enteros, esto es, su cómputo ha de hacerse de fecha a fecha, lo que quiere decir que si un mes empieza a contarse en determinada fecha, en la misma del mes siguiente comenzará un nuevo mes, o sea, que el último día del plazo es el inmediatamente anterior, o lo que es igual, que la fecha final (o guarismo que la representa) viene referida al día en que se produjo la notificación del acto o disposición» [STS de 4 de marzo de 1980 (ROJ: STS 1971/1980-ECLI:ES:TS:1980:1971)].

6. «El antiguo art. 7 del Código Civil establecía una forma igualitaria para el cómputo de los plazos por días o por meses y convertía los plazos por meses en plazos de treinta días. Por el contrario, los arts. 303 al 305 de la Ley de Enjuiciamiento Civil establecen un criterio distinto de cómputo según los plazos sean por días o por meses. Este diferente régimen de cómputo dio lugar a una vacilante jurisprudencia que aplicaba a los plazos computados por días el mismo criterio previsto para los que se computaban por meses, excluyendo el día que determinaba su iniciación y comenzaba el cómputo el día siguiente; pero toda discrepancia desapareció a raíz de la unificación que realizó en esta materia el Decreto-ley de 31 de mayo de 1974 que se dictó en uso de la autorización que había concedido el art. 1. ${ }^{\circ}$ de la Ley de Bases de 17 de marzo de 1973 para la modificación del título preliminar del Código Civil, en virtud de la cual el nuevo art. 5 de este Código acepta el sistema de la Ley de Enjuiciamiento Civil 
acorde con el del art. 60 de la Ley de Procedimiento Administrativo, en el que la norma de excluir el primer día se configura como regla que solamente puede aplicarse al plazo señalado por días, como claramente explica el preámbulo de dicho Decreto-ley y confirma el texto del mencionado art. 5; debiendo aplicarse esta regla de excluir el primer día al plazo señalado por meses, pues éstos se computan de "fecha a fecha" y a esta frase no se le puede atribuir otro significado que el de entender que el plazo vence el mismo día de la notificación o publicación del mes correspondiente, es decir, que notificado el acto el día 12 de diciembre de 1984, si el plazo para la interposición del recurso contencioso es de dos meses, ese plazo concluye el día 12 del mes de febrero. Si se interpone el recurso contencioso-administrativo el día 13 de dicho mes es evidente la extemporaneidad de la interposición y la inadmisibilidad del recurso contencioso-administrativo por ello, a tenor de art. 82.f) de la Ley de la Jurisdicción [...] Esta es la doctrina constante de este Alto Tribunal, como puede verse del Auto de esta Sala de 17 de octubre de 1986 y de las Sentencias también de esta Sala de 19 de julio, 21 de noviembre y 2 de diciembre de 1985, y las muchas que la última indica». En el supuesto concreto, notificado el acuerdo impugnado el 12 de diciembre de 1984 e interpuesto el recurso jurisdiccional el 13 de febrero de 1985, la STS declara su inadmisibilidad «por dolorosa que pueda resultar tal conclusión, pues la claridad y la reiteración de los preceptos y de la doctrina no permiten distinta interpretación; siendo por otra parte evidente que ha sido el actuar negligente de la parte lo único que aquí determina la aludida aplicación al no haberse atenido al amplio plazo de los dos meses que establece el expresado art. 58.1 de la Ley de la Jurisdicción, siendo evidente que por encima del caso concreto está la seguridad jurídica protegida por la Constitución (su art. 9.3) y su salvaguardia corresponde a los tribunales en la aplicación de las leyes (art. 5.1 de nuestra Ley Orgánica), sin que pueda invocarse el principio pro actione para romper la seguridad jurídica quebrantando un plazo fijado por la Ley» [STS de 17 de noviembre de 1987 (ROJ: STS 9585/1987-ECL I:ES:TS:1987:9585)].

Como expresamente declara la STS de 4 de marzo de 1980 antes citada, el cómputo del plazo de fecha a fecha quiere decir «que si un mes empieza a contarse en determinada fecha, en la misma del mes siguiente comenzará un nuevo mes, o sea, que el último día del plazo es el inmediatamente anterior, o lo que es igual, que la fecha final (o guarismo que la representa) viene referida al día en que se produjo la notificación del acto 
o disposición». O, como resume la Sentencia de 17 de noviembre de 1987 —igualmente antes citada - a la frase cómputo de «fecha a fecha» «no se le puede atribuir otro significado que el de entender que el plazo vence el mismo día de la notificación o publicación del mes correspondiente».

\section{SITUACIÓN ACTUAL}

El sistema de cómputo de los plazos por meses de fecha a fecha sigue siendo el aplicado en la actualidad. La posición mayoritaria en el Tribunal Supremo entiende que el dies ad quem del plazo coincide, en el mes que corresponda, con la fecha de la notificación o publicación del acto y, también mayoritariamente, se entiende que el dies a quo del plazo es el día siguiente al de la notificación o publicación. Ello no obstante, también pueden citarse sentencias que consideran que el dies a quo es el mismo día de la notificación. Por último, cabe mencionar que existe una postura que considera que el plazo se inicia el día siguiente al de la notificación o publicación, pero que concluye no el día que coincide con el de la notificación, sino el siguiente, de manera que, en este caso, el cómputo de fecha a fecha lo es de fecha de inicio a fecha de fin del plazo.

La cuestión no es baladí, pues mientras el trámite efectuado el último día del plazo está dentro del mismo y, por tanto, será eficaz, el realizado al día siguiente está ya fuera del plazo y, en principio - con las salvedades establecidas en la ley-, será ineficaz. De ahí que la diferencia de un día en la determinación del dies ad quem pueda tener trascendental importancia al ser determinante de que se entre a conocer del fondo del asunto o se dicte una decisión de inadmisión sin entrar, por tanto, a decidir sobre el fondo, lo que podría afectar al derecho a la tutela judicial efectiva (art. $24 \mathrm{CE})$.

\section{a) El plazo comienza el dia siguiente de la notificación y concluye en el día que coincide con el de la notificación}

La postura seguida mayoritariamente por el Tribunal Supremo considera que el plazo señalado por meses comienza el día siguiente a la fecha de la notificación o publicación y concluye el día ordinal anterior del mes correspondiente, que coincide con el ordinal de la notificación o publicación del acto, de manera que el concepto de «fecha a fecha» es de fecha 
de notificación — que no de inicio del plazo— a fecha de finalización del plazo.

La Sentencia del Tribunal Supremo de 8 de marzo de 2006 [Sec. 3. , rec. 6767/2003, ponente D. José Manuel Bandrés Sánchez-Cruzat (ROJ: STS 2251/2006-ECLI:ES:TS:2006:2251)], entre otras muchas, sigue este criterio. La STS estima el recurso de casación interpuesto frente a la Sentencia de la Sala de lo Contencioso-Administrativo del Tribunal Superior de Justicia de Canarias de 9 de julio de 2003 y sintetiza la doctrina jurisprudencial en los siguientes términos: «Cuando se trata de plazos de meses (o años) el cómputo ha de hacerse según el art. 5 del Código Civil, de fecha a fecha, para lo cual, aun cuando se inicie al día siguiente de la notificación o publicación del acto o disposición, el plazo concluye el día correlativo a tal notificación o publicación en el mes (o año) de que se trate. El sistema unificado y general de cómputos así establecido resulta el más apropiado para garantizar el principio de seguridad jurídica», y añade: «El cómputo del día final, de fecha a fecha, cuando se trata de un plazo de meses no ha variado y sigue siendo aplicable, según constante jurisprudencia recaída en interpretación del art. 46.1 de la vigente Ley Jurisdiccional, de modo que el plazo de dos meses para recurrir ante esta jurisdicción un determinado acto administrativo, si bien se inicia al día siguiente, concluye el día correlativo al de la notificación en el mes que corresponda».

Como afirma, entre otras, la Sentencia del Tribunal Supremo de 4 de marzo de 1992 [Sec. 1. a, rec. no consta, ponente D. Angel Alfonso Llorente Calama (ROJ: STS 16091/1992-ECLI:ES:TS:1992:16091)], «si un mes comienza a contarse en determinada fecha, en la misma del mes siguiente comenzará un nuevo mes, o sea, que el último día del plazo es el inmediatamente anterior»; por ello entiende esta STS que «el cómputo del plazo de fecha a fecha se inicia al día siguiente de la notificación o publicación, y concluye el día correlativo al de la notificación o publicación $[\ldots]$ y no al siguiente».

\section{b) El plazo comienza el mismo día de la notificación y concluye el día que coincide con el de la notificación}

Según antes se ha adelantado, también existen sentencias del Tribunal Supremo que entienden que el plazo, si bien concluye el día ordinal de la notificación en el mes que corresponda, comienza el mismo día de la notificación o publicación. 
En esta postura se enmarca la Sentencia del Tribunal Supremo de 19 de diciembre de 2008 [Sec. 2. ${ }^{a}$, rec. 130/2004, ponente D. Manuel Vicente Garzón Herrero (ROJ: STS 7520/2008-ECLI:ES:TS:2008:7520)], dictada en recurso de casación para la unificación de doctrina. La STS estima el recurso interpuesto frente a sentencia del Tribunal Superior de Justicia de Navarra, que había entendido que, habiéndose notificado el acto administrativo el 16 de marzo, la reclamación interpuesta el siguiente 16 de abril lo era fuera del plazo de un mes establecido al efecto y, como las sentencias de contraste aportadas, entiende, por el contrario, que la interposición en la misma fecha de la notificación, el mes siguiente, es realizada en plazo. La STS se remite a una «jurisprudencia consolidada de esta Sala» y cita expresamente la Sentencia de fecha 31 de mayo de 1997 en la que, efectuada «correctamente la notificación el día 20 de junio de 1988, el último día para interponer el recurso de reposición era el día 20 de julio del mismo año y no el 21 de este mes». La STS, en relación con la fecha inicial del cómputo del plazo, afirma que «el plazo del mes comienza a contarse el mismo día de la notificación o publicación del acto o disposición impugnados» ${ }^{7}$.

No obstante haberse dictado la anterior STS en recurso para la unificación de doctrina, lo cierto es que, con posterioridad, el TS ha vuelto a la postura tradicional de considerar que el plazo comienza el día siguiente de la notificación o publicación. Así ocurre con la Sentencia del Tribunal Supremo de 19 de julio de 2009 (Sec. 4. ${ }^{a}$, rec. 215/2009, ponente D. Antonio Martí García) que afirma que «es reiteradísima la doctrina de esta Sala sobre los plazos señalados por meses que se computan de fecha a fecha, iniciándose el cómputo del plazo al día siguiente de la notificación o publicación del acto, pero siendo la del vencimiento la del día correlativo mensual al de la notificación».

\section{c) El plazo comienza el día siguiente de la notificación y concluye el día que coincide con el siguiente al de la notificación}

Finalmente, otra postura entiende que el plazo comienza el día siguiente al de la fecha de la notificación o publicación y termina en el mes corres-

\footnotetext{
7 Con la vigencia de la Ley de Procedimiento Administrativo de 1958, la STS de 17 de noviembre de 1987 — ya citada — también parece considerar que el plazo empezaba el mismo día de la notificación o publicación.
} 
pondiente en la misma fecha en que comienza, es decir, el día ordinal siguiente al de la notificación.

Con base en la redacción del art. 48.2 de la Ley 30/1992, de 26 de noviembre, tras la modificación de la Ley 4/1999, de 13 de enero, que establece que si el plazo se fija en meses éstos se computarán «a partir del día siguiente a aquel en que tenga lugar la notificación o publicación del acto de que se trate» y que «si en el mes de vencimiento no hubiera día equivalente a aquel en que comienza el cómputo, se entenderá que el plazo expira el último día del mes», la Sentencia de la Sala de lo Contencioso-Administrativo del Tribunal Superior de Justicia de Madrid de 1 de abril de 2009 (Sec. 3. . , rec. 40/2009, ponente D. Juan Ignacio Pérez Alférez) afirma que «esta Sección viene entendiendo de forma mayoritaria, atendiendo al tenor literal de la nueva redacción del art. 48 que ha suprimido del apartado 2 la expresión de "fecha a fecha" y al principio pro actione, que el cómputo se inicia a partir del día siguiente a aquel en que tenga lugar la notificación o publicación del acto y que finaliza en el día equivalente del mes a aquel en que comienza el cómputo, tal como resulta del tenor literal del precepto que se estima claro, por lo que notificada la resolución sancionadora el 22 de mayo de 2006, el plazo para la interposición del recurso de alzada comenzaba a computarse desde el día 23 de mayo de 2006 y finalizaba el 23 de junio de 2006».

Al margen de sentencias de órganos inferiores, también el Tribunal Supremo, en alguna ocasión, ha considerado que el plazo finalizaba en la fecha que coincidía con la del día siguiente al de la notificación o publicación. Así, la STS de 24 de junio de 2011 (Sec. 4. ${ }^{a}$, rec. 2899/2007, ponente D. Enrique Lecumberri Martí), partiendo de que la notificación se produce el día 7 de octubre de 1999, afirma que «[e]l dies a quo comenzaba a partir del día siguiente en que procedió aquella notificación, es decir, el 8 de octubre de 1999, pues, según la regla tradicional dies a quo non computator in termino, los plazos para interponer recursos administrativos y contencioso-administrativos se contarán a partir del día siguiente a aquel en que tenga lugar la notificación o publicación del acto de que se trate —art. 48.4 de la Ley 30/1992 — y el dies ad quem termina el último día del plazo que sea hábil, pues, cuando sea inhábil, se entenderá prorrogado el plazo al primer día hábil siguiente», concluyendo en el caso concreto que el plazo — de un año- concluía el día 8 de octubre de 2000, y siendo «un hecho incuestionable que el día 8 de octubre de 2000 era domingo y el día siguiente era festivo en la Comunidad Valenciana [...] la reclamación por responsabilidad patrimonial [presentada el 10 de octu- 
bre de 2000] se formuló dentro del plazo establecido en el art. 142.4 de la tantas veces citada Ley 30/1992».

También el Tribunal Constitucional se ha sumado en ocasiones a esta postura. La STC 108/2004, de 30 de junio (Pleno, rec. 3907/1996, ponente $\mathrm{D} .{ }^{a}$ Elisa Pérez Vera), en relación con la interposición del recurso de inconstitucionalidad, rechaza la extemporaneidad alegada por el abogado del Estado, afirmando, con remisión a su STC 48/2003, de 12 de marzo, que si la norma impugnada se publicó en el BOE de 30 de julio de 1996, el plazo de tres meses previsto en el art. 33 de la Ley Orgánica del Tribunal Constitucional (LOTC) vencía el día 31 de octubre siguiente. Por su parte, la Sentencia del Tribunal Constitucional 48/2003, de 12 de marzo (Pleno, rec. 5550/2002, ponente D. Manuel Jiménez de Parga y Cabrera), partiendo de que el recurso se registró en el TC el día 30 de septiembre de 2002, afirma que estaría vencido el plazo de tres meses establecido en el art. 33.1 LOTC, «si se entiende que el término a quo era la fecha de publicación oficial de la ley [impugnada], esto es, el 28 de junio anterior, lo que situaría el dies ad quem en el 28 de septiembre de 2002», pero que, «sin embargo, si se entiende que el dies a quo es el día siguiente al de la publicación oficial, el término ad quem sería el 30 de septiembre, dado que el 29 era domingo». Y añade: «Pues bien, en relación a esta cuestión, el texto del art. 33 LOTC posibilita ambas interpretaciones al disponer que "el recurso de inconstitucionalidad se formulará dentro del plazo de tres meses a partir de la publicación de la Ley, disposición o acto con fuerza de Ley impugnado". Así, en la STC 148/1991, de 4 julio, efectuamos el cómputo a partir del día siguiente al de la publicación (FJ 2. ${ }^{\circ}$ ). Aplicando el mismo criterio, hemos de entender, en virtud del principio pro actione y a semejanza de lo que sucede con el cómputo de los plazos en el recurso de amparo, que el dies a quo es el siguiente al de la publicación oficial de la Ley y que, por tanto, el recurso se presentó dentro de plazo».

\section{d) STC 209/2013, de 16 de diciembre}

Así las cosas, la cuestión fue planteada ante el Tribunal Constitucional por posible vulneración del derecho a la tutela judicial efectiva en su vertiente de acceso a la jurisdicción, por declararse la extemporaneidad del recurso — administrativo - por haber sido presentado al día siguiente de expirar el plazo con arreglo a la postura tradicional del Tribunal Supremo, lo que impidió entrar a conocer del fondo de la cuestión. 
El Ministerio Fiscal se mostró favorable a la concesión del amparo solicitado, según se recoge en los antecedentes de la propia STC, porque, en síntesis, «la interpretación cuestionada, aunque mayoritaria y reiterada, no es unánime ni mucho menos la única posible; es contradictoria, por perpetuar una fórmula de cómputo por meses naturales y admitir simultáneamente que el cómputo incluye los días inicial y final cuando el plazo empieza a correr en la fecha de la notificación; admite y requiere una interpretación favorable al derecho a la tutela judicial efectiva; produce el efecto de sustraer un día al plazo fijado por la ley, lo que impide disfrutar en su integridad del tiempo concedido. Supondría, por tanto, una aplicación rigorista y contraria al art. 24.1 CE». Sin embargo, la sentencia (STC, Sala 1. ${ }^{a}, 209 / 2013$, de 16 de diciembre, rec. 2354/2012, ponente D. Andrés Ollero Tassara) deniega el amparo.

Afirma el Tribunal Constitucional que la controversia no se refiere a que el plazo se haya computado de «fecha a fecha», sino al día que debía tomarse como referencia para aplicarlo y entiende que

«no puede considerarse irrazonable el criterio de la Sentencia de la Audiencia Nacional [...] por considerar que el plazo para interponerlo expiró el día cuyo ordinal coincidía con el de la notificación de la resolución [...] En plazos señalados por días, para asegurar que el ciudadano disponga del tiempo que marca la ley, es sin duda necesario llevar el dies a quo al día siguiente al de la notificación; de otro modo, se hurtaría al recurrente de un tramo del término: las horas transcurridas hasta la práctica de la indicada notificación. Sin embargo, en plazos señalados por meses o años no es preciso a estos efectos trasladar el dies a quo al día siguiente al de la notificación. Puede afirmarse gráficamente que, por lo mismo que de lunes a lunes hay más de una semana (ocho días, no siete), de 26 de enero a 26 de febrero hay más de un mes, sin que, en principio, se le haya privado al demandante de parte del plazo mensual que le correspondía por el hecho de que el dies ad quem se identificara con el día equivalente al de la notificación».

Y continúa:

«Los preceptos aplicados en el presente caso (arts. 241.1 LGT y 48.2 LPC) establecen que el plazo de impugnación empieza a correr a partir del día siguiente al de la notificación. No obstante, tampoco resulta irrazonable interpretar, como hace la Sentencia impugnada, que el ordinal del dies ad quem coincide con el del día en que se practicó la notificación: por lo mismo que de martes a lunes hay una semana, de 27 de enero — que es el día siguiente al de la notificación- a 26 de febrero hay el mes legalmente 
garantizado para la interposición del recurso de alzada, que era en este caso un presupuesto procesal del acceso a la jurisdicción contencioso-administrativa. Lo afirma la Sentencia recurrida cuando, apoyándose en la consolidada jurisprudencia del Tribunal Supremo, insiste en que el art. 241 LGT y la nueva redacción del art. 48.2 LPC (dada por la Ley 4/1999, de 13 de enero) han alterado el día inicial de cómputo, pero no la fecha de vencimiento, que sigue siendo el día correlativo al de la notificación en el mes que corresponda. Dicho de otro modo, establecido que el dies a quo es el siguiente al de la notificación, si se llevase el dies ad quem al día equivalente del mes siguiente se daría al administrado más tiempo del que marca la ley».

El TC reconoce que «el órgano judicial pudo tomar en consideración una interpretación más favorable en cuanto a la interposición en plazo del recurso de alzada» y que «los preceptos señalados soportaban la interpretación de que el vencimiento se produjo el primer día hábil equivalente al siguiente al de la notificación, que fue el 28 de febrero [...] Ahora bien, una cosa es que quepan varias interpretaciones y otra bien distinta que la Audiencia Nacional, al computar de un modo que permite al administrado disponer del plazo mensual que le otorga la ley para interponer el recurso de alzada, haya vulnerado el art. 24.1 CE».

Y concluye que no existe vulneración del derecho fundamental invocado porque la sentencia impugnada «se limita a aplicar el art. 58.1 de la Ley de la Jurisdicción Contencioso-Administrativa de 1956, que, como se decía en la STC 32/1989, de 13 de febrero, contempla el cómputo del plazo de dos meses para la interposición del recurso «de acuerdo con el sistema de "fecha a fecha", según el cual el plazo se inicia al día siguiente de la notificación y tiene como último día hábil el del mes correspondiente que coincida con aquel en que se realizó la notificación (FJ 3..$\left.^{\circ}\right)$ ». Afirma en este sentido que «es doctrina mayoritaria de la Sala Tercera del Tribunal Supremo que, a fin de que no se compute dos veces una misma fecha, el plazo de los dos meses que el art. 58 de la Ley Jurisdiccional establece para la interposición del recurso contencioso-administrativo, si bien se cuenta desde el día siguiente a la notificación de la resolución que se pretende recurrir, termina el día en que se cumplan los dos meses pero contado desde la misma fecha de la notificación (Sentencia de 6 de junio de 2000)». Dicho de otro modo, «que en los plazos que se cuentan por meses, el plazo concluye, ya dentro del mes correspondiente, el día que se designa con la misma cifra que identifica el día de la notificación o publicación». 
e) Previsión en la nueva Ley 39/2015, del Procedimiento Común de las Administraciones Públicas

El art. 30 de la Ley 39/2015, de 1 de octubre, del Procedimiento Administrativo Común de las Administraciones Públicas, dedicado al cómputo de los plazos, establece lo siguiente:

«1. Salvo que por Ley o en el Derecho de la Unión Europea se disponga otro cómputo, cuando los plazos se señalen por horas, se entiende que éstas son hábiles. Son hábiles todas las horas del día que formen parte de un día hábil.

Los plazos expresados por horas se contarán de hora en hora y de minuto en minuto desde la hora y minuto en que tenga lugar la notificación o publicación del acto de que se trate y no podrán tener una duración superior a veinticuatro horas, en cuyo caso se expresarán en días.

2. Siempre que por Ley o en el Derecho de la Unión Europea no se exprese otro cómputo, cuando los plazos se señalen por días, se entiende que éstos son hábiles, excluyéndose del cómputo los sábados, los domingos y los declarados festivos.

Cuando los plazos se hayan señalado por días naturales por declararlo así una ley o por el Derecho de la Unión Europea, se hará constar esta circunstancia en las correspondientes notificaciones.

3. Los plazos expresados en días se contarán a partir del día siguiente a aquel en que tenga lugar la notificación o publicación del acto de que se trate, o desde el siguiente a aquel en que se produzca la estimación o la desestimación por silencio administrativo.

4. Si el plazo se fija en meses o años, éstos se computarán a partir del día siguiente a aquel en que tenga lugar la notificación o publicación del acto de que se trate, o desde el siguiente a aquel en que se produzca la estimación o desestimación por silencio administrativo.

El plazo concluirá el mismo día en que se produjo la notificación, publicación o silencio administrativo en el mes o el año de vencimiento. Si en el mes de vencimiento no hubiera día equivalente a aquel en que comienza el cómputo, se entenderá que el plazo expira el último día del mes.

5. Cuando el último día del plazo sea inhábil, se entenderá prorrogado al primer día hábil siguiente».

Por tanto, la Ley 39/2015 en el cómputo de los plazos por meses —al igual que la Ley 30/1992 en la redacción dada por la Ley 4/1999- no hace referencia al cómputo «de fecha a fecha», y también como en ésta se fija el 
dies a quo en el siguiente al de la notificación o publicación o en que se produzca la estimación o la desestimación por silencio administrativo. Ahora bien, en la Ley 39/2015 — a diferencia de lo que ocurría en la Ley 30/1992se fija también el dies ad quem, estableciéndose expresamente que «el plazo concluirá el mismo día en que se produjo la notificación, publicación o silencio administrativo en el mes o el año de vencimiento». Con ello pretende acabarse con los problemas derivados de la ausencia de una definición legal del significado de la expresión «cómputo de fecha a fecha» y fundamentalmente de la omisión de determinación del dies ad quem.

\section{CONCLUSIÓN}

El cómputo de los plazos por meses enteros o naturales acabó denominándose «cómputo de fecha a fecha», pues su cómputo iba de determinada fecha (guarismo) a igual fecha (guarismo) del mes que correspondiere. Si la expresión explica gráfica y sencillamente el cómputo del plazo adolece de precisión técnica, pues las fechas tenidas en cuenta no son las de inicio y fin del plazo — como la expresión induce a pensar-, sino las de notificación (que no de inicio del plazo) y la de fin del plazo.

La expresión se trasladó a los textos legales ${ }^{8}$, pero dada la ausencia en estas mismas leyes de una definición de dicho concepto (no se especifica de qué fecha a qué fecha debe realizarse el cómputo), la imprecisión sobre el dies a quo (la exclusión del día de notificación o publicación del cómputo del plazo ¿̇e aplica sólo a los plazos por días o también a los señalados por meses?), y la indefinición del dies ad quem (no se concreta cuál es el día final. sino que se establece simplemente la previsión para el caso de que en el mes de vencimiento no exista día equivalente al inicial del cómputo) dio lugar a posturas discrepantes.

La cuestión del cómputo de los plazos por meses se planteó ante el Tribunal Constitucional que, en síntesis, si bien reconoce que los preceptos soportaban la interpretación de que la fecha de vencimiento del plazo coincida con la siguiente a la de la notificación, concluye que la postura seguida mayoritariamente por el Tribunal Supremo no puede considerar-

${ }^{8}$ Ley de Procedimiento Administrativo de 1958, reforma del título preliminar del Código Civil de 1974 y Ley de Régimen Jurídico de las Administraciones Públicas y del Procedimiento Administrativo Común de 1992. La reforma de esta última ley llevada a cabo en 1999 elimina la expresión que, sin embargo, sí aparece en la Ley de Enjuiciamiento Civil del año siguiente (2000). 
se irrazonable ni arbitraria, por lo que no es contraria al derecho a la tutela judicial efectiva.

La Ley 39/2015, en relación con los plazos por meses, no recoge expresamente el cómputo «de fecha a fecha»; por el contrario, sí fija expresamente tanto el dies a quo —el plazo se computa a partir del día siguiente a aquel en que tenga lugar la notificación o publicación o producción de los efectos del silencio administrativo- como el dies ad quem —el plazo concluirá el mismo día en que se produjo la notificación, publicación o silencio administrativo en el mes de vencimiento- con lo que, en principio, priva de fundamento la tesis que entendía que el plazo se iniciaba al día siguiente al de la notificación y concluía también en la misma fecha, lo que se argumentaba, entre otras razones, en que la Ley 30/1992 establecía que si el plazo se fija en meses se computarán a partir del día siguiente al de la notificación y que «si en el mes de vencimiento no existiera día equivalente a aquel en que comienza el cómputo, se entenderá que el plazo expira el último día del mes», previsión que, sorprendentemente, sigue manteniendo el art. 30 de la Ley 30/2015, a pesar de que previamente ha afirmado que el día final del cómputo no coincide con el inicial, sino con el de la notificación, publicación o silencio administrativo, por lo que la previsión de inexistencia debería ir referida a éste. 